\title{
Understanding deprescribing of preventive cardiovascular medication: a Q-methodology study in patients
}

This article was published in the following Dove Press journal:

Patient Preference and Adherence

23 May 2017

Number of times this article has been viewed

Clare H Luymes'

Nelleke J Boelhouwer'

Rosalinde KE Poortvliet'

Wouter de Ruijter'

Ria Reis ${ }^{1-3}$

Mattijs E Numans'

'Department of Public Health and Primary Care, Leiden University Medical Center, Leiden, ${ }^{2}$ Amsterdam Institute for Social Science Research, University of Amsterdam, Amsterdam, the Netherlands; ${ }^{3}$ The Children's Institute, University of Cape Town, Cape Town, South Africa
Correspondence: Clare H Luymes Department of Public Health and Primary Care (V-0-P), Leiden University Medical Center, PO Box 9600, 2300 RC Leiden, the Netherlands

$\mathrm{Tel}+3|7| 5268444$

Fax +3I 7I 5268259

Email c.h.luymes@lumc.nl
Background: Patients with low cardiovascular disease (CVD) risk potentially use preventive cardiovascular medication unnecessarily. Our aim was to identify various viewpoints and beliefs concerning the preventive CVD management of patients with low CVD risk using preventive cardiovascular medication. Furthermore, we investigated whether certain viewpoints were related to a preference for deprescription or the continuation of preventive cardiovascular medication.

Methods: In 2015, we purposively sampled patients from the intervention arm of the Evaluating Cessation of STatins and Antihypertensive Treatment In primary Care (ECSTATIC) trial in the Netherlands for this study. Participants made Q-sorts by ranking 43 statements concerning preventive CVD management from "totally disagree" to "totally agree". These Q-sorts were analyzed using PQMethod 2.35 software. A varimax procedure presented the distinguishing viewpoints that were favored by our participants. We used group discussion quotations to underline our findings. For validation purposes, we asked participants how well each viewpoint fitted them.

Results: Of 291 invited patients, 33 participated. Thirty-one Q-sorts were analyzed. The following three viewpoints were found: 1) a controlling viewpoint, in which patients held the belief that monitoring blood pressure and cholesterol levels is important $(n=13$, of which seven had their medication deprescribed and six continued their medication); 2) an autonomous viewpoint, in which patients showed a dislike of medication $(n=8$, of which seven had their medication deprescribed and one had it continued); and 3) an afraid viewpoint, in which patients were fearful of developing CVD ( $n=8$, of which two had their medication deprescribed and six had it continued). Seventy-four percent of the participants believed that the viewpoint to which they were assigned was a good fit.

Conclusion: Three well-discriminating viewpoints about preventive CVD management were determined. Knowing and recognizing these viewpoints is effective for general practitioners when discussing the deprescribing of preventive cardiovascular medications with patients and may be used to promote implementation of deprescription.

Keywords: general practice, preventive medicine, cardiovascular diseases, antihypertensive agents, anticholesteremic agents, inappropriate prescribing

\section{Introduction}

According to the guidelines of many countries, patients with predicted low cardiovascular disease (CVD) risk do not require medication to prevent CVD. ${ }^{1-6}$ Nonetheless, preventive cardiovascular medication is often prescribed and used by patients with lower levels of predicted CVD risk than the actual guideline thresholds, because 
recommendations for drug initiation have been revised after treatment has been started. ${ }^{7,8}$ Deprescribing these potentially inappropriate medications can reduce unnecessary adverse reactions in patients and undue medical costs. In an earlier study, we identified the barriers and enablers that patients and general practitioners (GPs) mention during consultations in which the deprescribing of preventive cardiovascular medication is discussed. ${ }^{9}$ Patients expressed doubts about the appropriateness of their medication and seemed to rely on the information and expertise of their GP in determining whether deprescribing was justified. This finding was also observed in other studies. ${ }^{10-12}$ Furthermore, a general dislike of medication and knowing that follow-up care was available and medication could be restarted are known to be enablers of deprescribing. 9,13 Patients' expectations of the long-term medications they use play a role in their willingness to have their preventive medication deprescribed. Dohnhammar et $\mathrm{al}^{14}$ reported that patients use medication to care for themselves above and beyond lifestyle changes alone and that they tend to overestimate the risk-lowering effects of preventive medication. Furthermore, patients and doctors balance risks and benefits of medication in a different way. For example, benefits in the short term are identified as more important to patients compared with doctors. ${ }^{14}$ Patients' views on deprescribing their medication can thus be different than their physicians' views, but patient viewpoints could influence the implementation of preventive CVD management. Therefore, our objective was to identify various viewpoints and beliefs in patients with low CVD risk using preventive cardiovascular medication concerning preventive CVD management. Hence, we performed a Q-methodological study in patients with low CVD risk who had discussed deprescribing their preventive cardiovascular medication with their GP.

\section{Methods \\ Q-methodology}

To investigate the viewpoints of patients with low CVD risk concerning their preventive CVD management, a Q-methodological study was conducted. Q-methodology combines the strengths of both qualitative and quantitative methods, which enables the conversion of subjective perspectives into an objective outcome. ${ }^{15}$ Although Q-methodology does not claim to identify viewpoints that are consistent within individuals across time, it is expected that viewpoints should show some degree of consistency over time. Hence, for the possible future implementation of a deprescribing policy, Q-methodology seems to be an appropriate way to investigate whether certain viewpoints are related to a preference for deprescription or for the continuation of preventive cardiovascular medication. ${ }^{15}$ In contrast to qualitative analyses, Q-methodology focuses on groups instead of individuals, and therefore on the variety of viewpoints instead of on the viewpoint of the majority. It focuses on similarities and differences in a study population, resulting in various viewpoints or patterns of thought that specify a given population. The method consists of the following four steps, which we will further describe: 1) the determination of the concourse and generation of a Q-set, 2) the generation of a P-set (study population), 3) performing the Q-sorts, and 4) factor analysis and interpretation.

\section{Q-set}

The Q-set consisted of statements representing the concourse, the full range of contributions in the qualitative debate, on preventive CVD management. Statements were based on the literature,,$^{10,11,13}$ expert opinion and data from our previous study concerning the barriers and enablers that patients mention during deprescribing consultations with their GPs. ${ }^{9}$ Researchers (CHL, NLB, and RKEP) formulated 44 statements to cover the concourse. After testing the Q-set with four patients to determine the clarity of the statements and their sufficiency in displaying different viewpoints, a final Q-set of 43 statements was established. These were randomly numbered and printed on cards.

\section{P-set}

The study population was purposively sampled from the Evaluating Cessation of STatins and Antihypertensive Treatment In primary Care (ECSTATIC) trial (NTR3493). In the ECSTATIC trial (a randomized controlled trial that started in 2012, with follow-up ending in November 2015), we evaluated whether it is cost-effective and safe to deprescribe antihypertensive and lipid-lowering drugs in primary care patients for whom medication is not recommended according to the current Dutch guideline on Cardiovascular Risk Management (Box 1). Participants from the intervention practices were offered a consultation with their GP to discuss whether to deprescribe their preventive cardiovascular medication.

We sent written invitations to all patients from the intervention practices of the ECSTATIC trial $(n=291)$ living in and around the cities of Leiden and Alphen aan den Rijn. Based on the preferred dates, we organized five sessions: three with patients who stopped their preventive cardiovascular medication 2 years ago and who still received no preventive cardiovascular medication (the deprescription 


\section{Box I ECSTATIC trial}

The ECSTATIC trial evaluates whether it is cost-effective and safe to deprescribe antihypertensive and lipid-lowering drugs in primary care patients to whom medication is not recommended according to the current Dutch guideline on Cardiovascular Risk Management. Patients without CVD were included in the ECSTATIC trial when having low CVD risk and using antihypertensive and/or lipid-lowering drugs. GPs in the intervention practices received a training providing information about this guideline and its differences with respect to the former guideline. In preparation of the deprescribing consultations, there were presented cases of fictional low CVD risk patients and they discussed these patients' suitability to have their medication deprescribed.

GPs participating in the trial sent a written invitation to their patients without CVD, using potentially inappropriate antihypertensive and/or lipid-lowering drugs. After obtaining the informed consent, the researchers determined eligibility on the basis of the patients' pretreatment 10 -year risk of morbidity and mortality of CVD, using the SCORE risk function as well as their (possible) additional risk increasing factors (positive family history for CVD, obesity, decreased kidney function, and sedentary lifestyle) (I). When, based on the combination of the risk score and additional risk increasing factors for CVD, medication was not recommended according to the current guideline Cardiovascular Risk Management, patients were considered eligible for inclusion and were advised to make an appointment for a deprescribing consultation with their GP.

Abbreviations: ECSTATIC, Evaluating Cessation of STatins and Antihypertensive Treatment In primary Care; CVD, cardiovascular disease; GP, general practitioner.

group) and two with patients who had continued or restarted preventive cardiovascular medication or who had lowered their dose of their medication during the 2-year follow-up period (the continuation group).

\section{Q-sorts}

The sorting board that patients used to rank statements followed the Q-convention of a "forced normal distribution" (Figure S1).

Individual patients were given a pile of 43 statement cards and made piles containing statements with which they agreed, disagreed, or were neutral (no opinion or irrelevant). Next, each patient ordered the statements. On the extreme left, they placed the statements they disagreed with most. Next to those statements, they placed statements they disagreed with to a lesser extent, and so on. They did the same with the statements they agreed with most, except that these were placed on the right end of the sorting board. Finally, neutral statements were ordered and placed on the empty spots of the sorting board.

\section{Factor analysis and interpretation}

We analyzed the Q-sorts with PQMethod 2.35 software and used the varimax procedure to reveal the range of viewpoints that were favored by our study population. ${ }^{15}$ An algorithm was used to calculate how high the correlation coefficient must be and how much the correlation coefficient of the factor must differ from the correlation coefficient of the other factors to state that a person loads on to that specific factor. The patients loading on a specific factor are the patients with the most representative Q-sorts for this factor. ${ }^{16}$ Only the Q-sorts of patients loading on a specific factor were used for subsequent calculations. For each specific factor, an "ideal Q-sort" was created, showing how a hypothetical patient loading $100 \%$ on the factor would have ranked the statements. To interpret and name the factor, we used the $Z$-scores of the statements in these ideal Q-sorts, as well as the presented distinguishing and consensus statements of the factors. We reported statements distinguishing between any pair of factors with a $P$-value $<0.01$ (distinguishing statements) and statements not distinguishing between any pair of factors with a $P$-value $>0.01$ (consensus statements).

After patients ranked their statements on the sorting board and their informed consent was audiotaped, we asked them to reflect on their rank ordering. Their reflections and the following group discussions were audiotaped and used for the further interpretation of the factors. Due to a technical problem in one of the sessions, we had to leave one group discussion from the desprescription group out of our analysis.

We identified the distribution of patients from the deprescription and continuation group across the factors. A chi-square test was used to examine the significance of this distribution.

To validate the factors that resulted from the Q-methodology, we made factor descriptions highlighting the important distinguishing characteristics of the different factors. This validation questionnaire was sent to the patients. We asked them how well each factor description fitted them, using a five-point Likert scale ranging from "totally not" to "very well". The study was approved by the Medical Ethics Committee of the Leiden University Medical Center.

\section{Results}

Of the 291 invited patients, 33 were willing to participate. There were no statistically significant differences between the respondents and nonrespondents with regard to age or gender. Two patients were excluded from the analysis of the Q-sorts 
(incomplete Q-sort and language barrier). The characteristics of the patients who performed the Q-sort $(n=31)$ and of those who participated in the group discussions $(n=28)$ are shown in Table 1.

Table 2 shows the consensus and distinguishing statements in the Q-set. All patients had the idea that they could do something to reduce their CVD risk, even if CVD ran in their families (statement 5). Patients placed importance on a GP with good communication skills who explained their treatment options clearly (statement 12).

I feel that she shows interest in me as a patient and I always get a good advice, that is medically substantiated. [60-yearold female in the continuation group]

Another patient said:

When I go there [to the GP] I feel heard, and he takes time to explain things, and when he explains things to me, in the end, most of the time I don't even need medication, so, that's just really important to me. [66-year-old woman in the continuation group]

They did not feel medications were unnatural (statement 6), and all patients regarded hypertension management as one of the GPs' job responsibilities (statement 7).

In addition, three distinguishable factors emerged from the Q-sorts (Table 2), explaining 52\% of the variance in our data. The patients from the description and continuation groups were unequally distributed across these factors $(P=0.04)$.

\section{Factor I: controlling $(n=13$; seven from the deprescription group and six from the continuation group)}

Patients loading on this factor placed great importance on the periodical monitoring of blood pressure and cholesterol levels by their GP, whether they were using medication or not (statement 19). During group discussions, these patients expressed dissatisfaction with their GP on this point:
For years, I've been getting these repeated prescriptions, but no one [in the general practice] has ever said to me: let's measure your blood pressure [...] well, I think that is regrettable. [56-year-old woman in the continuation group]

If CVD ran in their families, they were more inclined to start using medication (statement 35):

I think that when it [blood pressure] is always really high and it is familial, you are more inclined to just continue taking that medication because in that case, it is different than just having [high blood pressure], well, yes. [66-year-old woman in the continuation group]

For patients loading on this factor, maintaining a healthy lifestyle was something obvious.

Being aware of what you eat, a bit of exercising, just the normal things. [62-year-old woman in the deprescription group]

Hence, they felt that nobody should smoke (statement 34). In addition, they easily maintained a healthy lifestyle, and they never sought professional help to live (even) healthier (statements 23 and 36 , respectively).

\section{Factor 2: autonomous ( $\mathrm{n}=8$; seven from the deprescription group and one from the continuation group)}

These patients would really appreciate living a long life without using medication, and they did not feel physically better when using medication (statements 33 and 21, respectively). Hence, they disagreed that using more and more medications comes along with growing old (statement 15). They disliked medication:

Throw it [medication] in the dustbin, that crap. [50-year-old woman in the deprescription group]

Furthermore, they were interested in the way that the medication worked, and they knew exactly why they did

Table I Characteristics of the patients who performed the Q-sort and of the patients who participated in the group discussions

\begin{tabular}{lll}
\hline Characteristics & $\begin{array}{l}\text { Q-sort patients } \\
(\mathbf{n = 3} \mathbf{l})\end{array}$ & $\begin{array}{l}\text { Group discussion patients (n=28), } \\
\text { the Netherlands, February and March 20 I 5 }\end{array}$ \\
\hline Male, $\mathrm{n}(\%)$ & $9(29.0)$ & $9(32.1)$ \\
Age, years, mean (SD) & $57.1(6.8)$ & $57.7(6.8)$ \\
Using/used antihypertensive medication, $\mathrm{n}(\%)$ & $18(58.1)$ & $16(57.1)$ \\
Using/used lipid-lowering drugs, $\mathrm{n}(\%)$ & $7(22.6)$ & $7(25.0)$ \\
Using/used both medications, $\mathrm{n}(\%)$ & $6(19.4)$ & $5(17.9)$ \\
Deprescription group, $\mathrm{n}(\%)$ & $17(54.8)$ & $13(46.4)$ \\
Continuation group, $\mathrm{n}(\%)$ & $14(45.2)$ & $15(53.6)$ \\
\hline
\end{tabular}


Table 2 Consensus and distinguishing statements in the Q-set and the values of the ideal Q-sort per factor

\begin{tabular}{|c|c|c|c|c|}
\hline No & Statements & $\begin{array}{l}\text { Q-sort value } \\
\text { factor I: } \\
\text { controlling }\end{array}$ & $\begin{array}{l}\text { Q-sort value } \\
\text { factor 2: } \\
\text { autonomous }\end{array}$ & $\begin{array}{l}\text { Q-sort value } \\
\text { factor 3: } \\
\text { afraid }\end{array}$ \\
\hline \multicolumn{5}{|c|}{ Consensus statements } \\
\hline I. & A healthy lifestyle is important to keep my CVD risk as low as possible* & 3 & 2 & 4 \\
\hline 2. & My individual CVD risk can change over time* & I & I & 0 \\
\hline 3. & $\begin{array}{l}\text { My own experiences and the ones from people around me were the most } \\
\text { important in my decision whether or not to deprescribe the medication for my } \\
\text { blood pressure/cholesterol level* }\end{array}$ & 0 & -1 & -1 \\
\hline 4. & $\begin{array}{l}\text { Medications for blood pressure/cholesterol level are very safe in comparison to } \\
\text { other kinds of medications* }\end{array}$ & -1 & -1 & 0 \\
\hline 5. & $\begin{array}{l}\text { If CVD runs in your family, you can do very little to prevent developing CVD } \\
\text { yourself** }\end{array}$ & -2 & -2 & -2 \\
\hline 6. & Medications are unnatural** & 0 & 0 & -1 \\
\hline 7. & $\begin{array}{l}\text { I feel a bit ashamed when I come to my GP for my blood pressure; he does not } \\
\text { have much time and should help patient who are really ill** }\end{array}$ & -2 & -3 & -4 \\
\hline 8. & I fear(ed) for side effects of blood pressure/cholesterol level lowering medication* & -1 & 0 & -1 \\
\hline 9. & I would rather use medication than change my lifestyle to reduce my CVD risk* & -4 & -4 & -3 \\
\hline 10. & $\begin{array}{l}\text { I am afraid that long-term use of medication for my blood pressure/cholesterol level } \\
\text { will have negative effects on } \mathrm{me}^{*}\end{array}$ & 0 & 0 & I \\
\hline II. & It is important that I can communicate well with my GP* & 2 & 3 & 2 \\
\hline 12. & $\begin{array}{l}\text { It is important that my GP clearly explains why I need a certain treatment, what the } \\
\text { options are, and how the medication works** }\end{array}$ & 4 & 3 & 3 \\
\hline \multicolumn{5}{|c|}{ Distinguishing statements } \\
\hline 13. & $\begin{array}{l}\text { I understand well why I do or do not use medication for high blood pressure/ } \\
\text { cholesterol level }\end{array}$ & 2 & $4 * * *$ & I \\
\hline 14. & I feel relieved when my cholesterol level is ok when it is checked & 1 & I & $4 * * *$ \\
\hline 15. & Using more and more medications just accompanies getting older & -2 & -3 & $0 * * *$ \\
\hline 16. & I know which food is healthy and will help me lowering my cholesterol level & 1 & $4 * * *$ & 1 \\
\hline 17. & If I experience less stressful events my blood pressure will be lower as well & 2 & 2 & $0 * * *$ \\
\hline 18. & I am interested in the mechanisms of different medications for high blood pressure & 0 & I & $-I^{* * * *}$ \\
\hline 19. & $\begin{array}{l}\text { It is important that my GP keeps monitoring my blood pressure, whether I use } \\
\text { medication or not }\end{array}$ & $4 * * *$ & $0 * * *$ & $2 * * *$ \\
\hline 20. & It is scary to walk around having a high blood pressure & $3 * * *$ & $-2^{* * * *}$ & $2 * * *$ \\
\hline 21. & $\begin{array}{l}\text { I feel physically better when I use medication for my blood pressure or } \\
\text { cholesterol level }\end{array}$ & 0 & $-4^{* * * *}$ & 0 \\
\hline 22. & $\begin{array}{l}\text { I do not make decisions concerning medication use alone, but together with my } \\
\text { partner/family/friends }\end{array}$ & -2 & 0 & $-2 * * *$ \\
\hline 23. & It is hard to maintain a healthy lifestyle & $-3 * * *$ & I & 2 \\
\hline 24. & $\begin{array}{l}\text { I would rather increase the dose of one medication than use a combination of two } \\
\text { medications in a lower dose }\end{array}$ & 0 & -1 & $-2 * * *$ \\
\hline 25. & I always read the information leaflet before I start using medication & I & I & $3 * * *$ \\
\hline 26. & I am afraid of developing a heart attack or stroke & -1 & 0 & $2 * * *$ \\
\hline 27. & Whether medication is reimbursed plays a role in my decision to use them or not & -3 & $-2^{* * * *}$ & -4 \\
\hline 28. & Doctors prescribe medication too easily & -2 & $0 * * *$ & -1 \\
\hline 29. & Using medication for my high blood pressure gives me a feeling of control & $0 * * *$ & -1 & -2 \\
\hline 30. & If I have a low risk of developing CVD I do not have to use medication to prevent it & I & $2^{* * *}$ & 0 \\
\hline 31. & It is just a small effort to take medication & 2 & $0 * * *$ & 1 \\
\hline 32. & I trust my GP in making the right decisions for me & I & $-I^{* * *}$ & 0 \\
\hline 33. & My wish is to become a 100 -year old without using medication & $0 * * *$ & $3^{* * *}$ & $-I^{* * *}$ \\
\hline 34. & Nobody should smoke & $3 * * *$ & I & 1 \\
\hline 35. & If CVD runs in my family I am more inclined to take medication & 2 & $-I^{* * *}$ & I \\
\hline 36. & $\begin{array}{l}\text { I have searched for help in order to achieve a healthier lifestyle (eg, help to stop } \\
\text { smoking, dietary advice, advice of a sports instructor) }\end{array}$ & $-3 * * *$ & $0 * * *$ & $3 * * *$ \\
\hline \multicolumn{5}{|c|}{ Remainder statements } \\
\hline 37. & Medications that lower blood pressure or cholesterol level are expensive & -1 & -1 & -2 \\
\hline 38. & $\begin{array}{l}\text { If my partner or good friend/colleague would advise me to continue my medication } \\
\text { then I would definitely do that }\end{array}$ & -1 & -2 & -3 \\
\hline
\end{tabular}

(Continued) 
Table 2 (Continued)

\begin{tabular}{|c|c|c|c|c|}
\hline No & Statements & $\begin{array}{l}\text { Q-sort value } \\
\text { factor I: } \\
\text { controlling }\end{array}$ & $\begin{array}{l}\text { Q-sort value } \\
\text { factor } 2 \text { : } \\
\text { autonomous }\end{array}$ & $\begin{array}{l}\text { Q-sort value } \\
\text { factor } 3 \text { : } \\
\text { afraid }\end{array}$ \\
\hline 39. & $\begin{array}{l}\text { I would appreciate it more if my GP decides for me whether or not I should use } \\
\text { medication than I would appreciate deciding that myself }\end{array}$ & -1 & -2 & -1 \\
\hline 40. & If my GP explains things to me, I am able to retell it when I am home & I & 2 & 0 \\
\hline $4 \mathrm{I}$. & Use of medications should be prevented or restricted as much as possible & 0 & 2 & I \\
\hline 42. & $\begin{array}{l}\text { I would want to reduce my CVD risk with alternative medicine such as homeopathy } \\
\text { or acupuncture }\end{array}$ & -1 & I & 0 \\
\hline 43. & $\begin{array}{l}\text { If I can stop my medication for high blood pressure/cholesterol level, I will continue } \\
\text { until the package is empty, otherwise it would be a waste }\end{array}$ & -4 & -3 & -3 \\
\hline
\end{tabular}

Notes: *Consensus statement that does not distinguish between any pair of factors with a $P$-value $>0.0$ I. **Consensus statement that does not distinguish between any pair of factors with a $P$-value $>0.05$. ***Distinguishing statement (the marker is placed at the $\mathrm{Q}$-sort value of the factor for which the statement is a distinguishing statement between any pair of factors with a $P$-value $<0.01$ ).

Abbreviations: CVD, cardiovascular disease; GP, general practitioner.

or did not use medication to lower their blood pressure or cholesterol levels (statements 18 and 13, respectively).

I Googled like crazy, especially when it was suggested to start medication, why is that necessary, what is the matter, what are the effects [of the medication], I did it [Google] far less when stopping it [the medication] was discussed. [54-year-old man in the deprescription group]

Having a high blood pressure did not scare them, whereas having a low cardiovascular risk was a reason for them to deprescribe preventive cardiovascular medication, even if CVD ran in their families (statements 20 and 35 , respectively). In contrast to the other factors, patients loading on this factor did not have that much confidence in the decisions their GP made for them (statement 32). These patients decided for themselves whether they would or would not use medication.

It was me [who made the decision to deprescribe]. The GP then checked whether it [deprescribing] was justified, and he said it was justified. Then I said, well, in that case I'll stop [the medication]. [64-year-old woman in the deprescription group]

\section{Factor 3: afraid ( $n=8$; two from the deprescription group and six from the continuation group)}

Patients loading on this factor felt relieved when their blood pressure or cholesterol test result was in order and were afraid to develop a stroke or heart attack (statements 14 and 26).

I'm scared I'll get a heart attack or a stroke, although I use medication, I will always have that fear. [68-year-old woman in the continuation group]
In contrast to the other factors, these patients did not hesitate to turn to professionals to help improve their lifestyle (statement 36). However, it was hard for them to change and maintain a healthy lifestyle (statement 23).

There is nothing as hard as changing your lifestyle.

[53-year-old man in the continuation group]

They were afraid of the negative effects of the longterm use of antihypertensive and lipid-lowering drugs (statement 10).

You take them [medications] because you think they will help you $[\ldots]$ what would be the negative effect in the long term, concerning my cholesterol pills that is not that clear to me. [47-year-old man in the deprescription group]

Furthermore, they always read the information leaflet of their medications (statement 25).

Table 3 Patients' $(n=31)$ reports on whether or not the three distinguishable factors that emerged from the Q-sorts fitted ${ }^{\text {ta }}$ them

\begin{tabular}{lllll}
\hline Patients & $\begin{array}{l}\text { Loading } \\
\text { on factor } \\
(\mathbf{n}=\mathbf{1 3})\end{array}$ & $\begin{array}{l}\text { Loading } \\
\text { on factor } \\
(\mathbf{n}=\mathbf{8})\end{array}$ & $\begin{array}{l}\text { Loading } \\
\text { on factor } \mathbf{3} \\
(\mathbf{n}=\mathbf{8})\end{array}$ & $\begin{array}{l}\text { Not } \\
\text { loading } \\
\text { on any } \\
\text { factor } \\
(\mathbf{n}=\mathbf{2})\end{array}$ \\
\hline Fitting factor I & $\mathbf{1 0}$ & 3 & 2 & $\mathrm{I}$ \\
Fitting factor 2 & 3 & $\mathbf{6}$ & 2 & $\mathrm{I}$ \\
Fitting factor 3 & $\mathrm{I}$ & 0 & $\mathbf{4}$ & 0 \\
Fitting just one factor & 9 & 5 & 4 & 0 \\
Fitting two factors & $\mathrm{I}$ & 2 & 2 & $\mathrm{I}$ \\
Fitting three factors & $\mathrm{I}$ & 0 & 0 & 0 \\
Not fitting any factor & 2 & 0 & $\mathrm{I}$ & 0 \\
Nonrespondents & 0 & $\mathrm{I}$ & $\mathrm{I}$ & $\mathrm{I}$ \\
\hline
\end{tabular}

Notes: ${ }^{\text {Well }}$ or very well. Bold data show the concordance between the factorloading according to analysis of the Q-sorts and the factor-fitting according to the patient. 


\section{Validation questionnaire}

The validation questionnaire was sent to 31 patients. A total of 29 patients responded. Of these, 27 loaded onto one of three factors (Table 3). In 74\% (20/27) of the cases, patients self-selected the factor they loaded on, indicating that this factor fitted them "well" or very well. Seven patients reported that more than one factor description contained elements matching their ideas.

\section{Discussion}

With our Q-methodology study, we aimed 1) to identify the viewpoints of patients with low CVD risk concerning preventive CVD management and 2) to investigate whether certain viewpoints were related to a preference for either the deprescription or continuation of preventive cardiovascular medication. We found the following three viewpoints: 1) controlling, 2) autonomous, and 3) afraid viewpoints. Patients who had their preventive cardiovascular medication deprescribed were differentially distributed across these viewpoints relative to patients who continued their medication. Most of the patients loading onto the autonomous viewpoint had their medication deprescribed, and most of the patients loading onto the afraid viewpoint had it continued. Several group discussion statements reinforced the findings of our Q-methodology, and in 74\% of the cases, patients selfselected the factor they loaded on as fitting them well.

\section{Strengths and limitations}

Using Q-methodology and postsort group discussions led to profound understanding of the factor arrays. The inclusion of patients who had deprescribed their medication and patients who had continued their medication ensured that different viewpoints were represented in our data. The participation grade of the study was fairly low, probably because of the fixed dates we offered for our sessions, combined with our working class population. However, as discussed by Watts and Stenner, ${ }^{15}$ our sample size was considered sufficiently large for a Q-methodological study to reveal some of the main viewpoints that were favored by our specific study population. Moreover, our study population was similar to the nonrespondents in terms of age and gender. Because of their participation in the ECSTATIC trial, it is possible that our study population had more negative views toward preventive cardiovascular medication use than patients generally have. The outcomes might therefore not be generalizable in that respect. The goal of this Q-methodological study, however, was to identify different patterns of thought in our specific population. One of the strengths of this study is that the study population had previously discussed deprescribing with their GPs. We believe that this ensured that their views and opinions were well thought-out, resulting in balanced outcomes. Furthermore, it enabled us to link the patients who had deprescribed or continued their medication with the factors we found, revealing a more defined image of the viewpoints of patients loading on these factors. This information may be helpful for implementation purposes. In addition, by asking all patients how well each factor fitted them, we were able to show that our factor description indeed represented the viewpoints of the patients within the study population.

\section{Comparison with existing literature}

Results from our Q-methodology overlap with the outcomes of several other studies. For example, similar observations had been made previously regarding the importance patients place on monitoring blood pressure and cholesterol ${ }^{10,13}$ (controlling and afraid), the role of stress as a cause of hypertension ${ }^{17}$ (controlling), the search for aides in changing one's lifestyle to reduce the effects of modifiable factors that influence blood pressure and cholesterol, ${ }^{10}$ and the fear of developing $\mathrm{CVD}^{17}$ (afraid). It is known that a dislike of medication and a lack of confidence in its prescriber are enablers of deprescribing. ${ }^{13,18}$ These characteristics were shared by the patients loading on the autonomous viewpoint, and these patients were indeed more likely to have their medication deprescribed. However, the fear of side effects is also known as an enabler of deprescribing, ${ }^{13}$ but patients loading onto the afraid viewpoint were more likely to continue their medication. This is likely because they feared CVD even more than the side effects, or because they were not able to change their lifestyle. ${ }^{14}$

Morecroft et $\mathrm{al}^{10}$ found that about half of the patients with hypertension believed that appropriate antihypertensive treatment involved leaving medical decisions to their GPs. Interestingly, all patients in our study population appreciated being involved in the general decision-making process. Considering the comparable age groups of both study populations, this may represent changing medical attitudes or cultural differences between patients in the UK and the Netherlands.

\section{Practice implications}

Knowing which views and thoughts patients have concerning preventive CVD management may be helpful for GPs when discussing this topic with a patient in daily practice. Furthermore, when planning to implement a deprescription strategy for inappropriate preventive cardiovascular medication, it 
Table 4 Suggested approaches for general practitioners to discuss preventive cardiovascular management

\begin{tabular}{|c|c|c|}
\hline Factor & Main features of the patient & Communication advice \\
\hline \multirow[t]{4}{*}{ Factor I: controlling } & Having a healthy lifestyle is something obvious & Discuss (treatment) options and explain why and how \\
\hline & Periodical monitoring of blood pressure/cholesterol & Focus the information on monitoring of blood \\
\hline & is important & pressure/cholesterol \\
\hline & No strong opinion regarding medication use & When the patient is indecisive, give your (expert) opinion \\
\hline \multirow[t]{3}{*}{ Factor 2: autonomous } & Knows a lot about medication and healthy lifestyles & Discuss (treatment) options and explain why and how \\
\hline & Little fear for cardiovascular disease & Focus the information on pros and cons of medication use \\
\hline & Negative toward medication use & Let the patient decide for themselves, eventually \\
\hline \multirow[t]{4}{*}{ Factor 3: afraid } & Changing and maintaining a (healthy) lifestyle is hard & Discuss (treatment) options and explain why and how \\
\hline & Fears cardiovascular disease & Focus the information on a healthy lifestyle and \\
\hline & & suggest professional help \\
\hline & No strong opinion regarding medication use & When the patient is indecisive, give your (expert) opinion \\
\hline
\end{tabular}

seems appropriate to start implementation in patients who have an autonomous viewpoint because deprescribing is most likely to be successful in this group of patients. We believe that this approach to start implementation will not be very time-consuming because most GPs can clearly identify the patients who fit this profile.

\section{Conclusion}

The three well-discriminating viewpoints concerning preventive CVD management that emerged from our Q-methodological study (controlling, autonomous, and afraid) can be used for implementation and communication purposes in deprescribing. Table 4 shows some suggestions on how to detect patients with certain viewpoints and how to optimally communicate with them.

\section{Acknowledgments}

The study received external funding from ZonMw, the Netherlands Organisation for Health Research and Development (reference number 200320017). The abstract of this article was presented at the North American Primary Care Research Group (NAPCRG) 2016 Annual Meeting as a poster presentation with interim findings. The poster's abstract was published on the website of NAPCRG: www.napcrg.org/ Conferences/AnnualMeeting/SearchEducationalSessions2016? $\mathrm{m}=6 \& \mathrm{~s}=18216$.

\section{Disclosure}

The authors report no conflicts of interest in this work.

\section{References}

1. Wiersma T, Smulders YM, Stehouwer CD, Konings KT, Lanphen J. Samenvatting van de multidisciplinaire richtlijn Cardiovasculair risicomanagement (herziening 2011) [Summary of the multidisciplinary guideline on cardiovascular risk management (revision 2011)]. Ned Tijdschr Geneeskd. 2012;156(36):A5104.
2. New Zealand Guidelines Group. New Zealand Cardiovascular Guidelines Handbook. 2nd ed. Wellington: New Zealand Guidelines Group; 2009:92.

3. National Heart Foundation of Australia (National Blood Pressure and Vascular Disease Advisory Committee). Guide to Management of Hypertension 2008. Updated December 2010. Canberra: Heart Foundation; 2010:30. Available from: http://heartfoundation.org.au/images/ uploads/publications/HypertensionGuidelines2008to2010Update.pdf. Accessed April 15, 2017.

4. Newcastle guideline Development and Research Unit; updated by the National Clinical Guideline Centre (formerly the National Collaborating Centre for Chronic Conditions) and the British Hypertension Society. Hypertension Clinical Management of Primary Hypertension in Adults. London: National Institute for Health and Clinical Excellence; 2011:34. Available from: http://www.ehs-egypt.net/pdf/WhatsnewNICE2011. pdf. Accessed April 15, 2017.

5. Gohlke H, Albus C, Bönner G, et al. Risikoadjustierte Prävention von Herz-und Kreislauferkrankungen [Risk-adjustedprevention of heart-and circulatory diseases]. Düsseldorf: Vorstand der Deutschen Gesellschaft für Kardiologie-Herz-und Kreislaufforschung eV; 2007:39. Available from: http://leitlinien.dgk.org/files/2007_Pocket-Leitlinien_Risikoadjustierte_Praevention.pdf. Accessed April 15, 2017.

6. Perk J, De Backer G, Gohlke H, et al. European Guidelines on cardiovascular disease prevention in clinical practice (version 2012). The Fifth Joint Task Force of the European Society of Cardiology and Other Societies on Cardiovascular Disease Prevention in Clinical Practice (constituted by representatives of nine societies and by invited experts). Eur Heart J. 2012;33(13):1635-1701.

7. van Duijn HJ, Belo JN, Blom JW, Velberg ID, Assendelft WJ. Revised guidelines for cardiovascular risk management - time to stop medication? A practice-based intervention study. Br J Gen Pract. 2011; 61(587):347-352.

8. Luymes CH, de Ruijter W, Poortvliet RK, et al. Change in calculated cardiovascular risk due to guideline revision: a cross-sectional study in the Netherlands. Eur J Gen Pract. 2015;21(4):217-223.

9. Luymes CH, van der Kleij RM, Poortvliet RK, de Ruijter W, Reis R, Numans ME. Deprescribing potentially inappropriate preventive cardiovascular medication: barriers and enablers for patients and general practitioners. Ann Pharmacother. 2016;50(6):446-454.

10. Morecroft C, Cantrill J, Tully MP. Individual patient's preferences for hypertension management: a Q-methodological approach. Patient Educ Couns. 2006;61(3):354-362.

11. Benson J, Britten N. Patients' decisions about whether or not to take antihypertensive drugs: qualitative study. BMJ. 2002;325(7369): 873.

12. Bezreh T, Laws MB, Taubin T, Rifkin DE, Wilson IB. Challenges to physician-patient communication about medication use: a window into the skeptical patient's world. Patient Prefer Adherence. 2012;6(1): $11-18$. 
13. Reeve E, To J, Hendrix I, Shakib S, Roberts MS, Wiese MD. Patient barriers to and enablers of deprescribing: a systematic review. Drugs Aging. 2013;30(10):793-807.

14. Dohnhammar U, Reeve J, Walley T. Patients' expectations of medicines-a review and qualitative synthesis. Health Expect. 2016;19(2): 179-193.

15. Watts S, Stenner P. Doing Q methodology: theory, method and interpretation. Qualitative Res Psychol. 2005;2(1):67-91.
16. Zabala A. qmethod: a package to explore human perspectives using Q methodology. R J. 2015;6(2):163-173.

17. Marshall IJ, Wolfe CD, McKevitt C. Lay perspectives on hypertension and drug adherence: systematic review of qualitative research. $B M J$. 2012;345:e3953.

18. Pound P, Britten N, Morgan M, et al. Resisting medicines: a synthesis of qualitative studies of medicine taking. Soc Sci Med. 2005;61(1): 133-155. 


\section{Supplementary material}

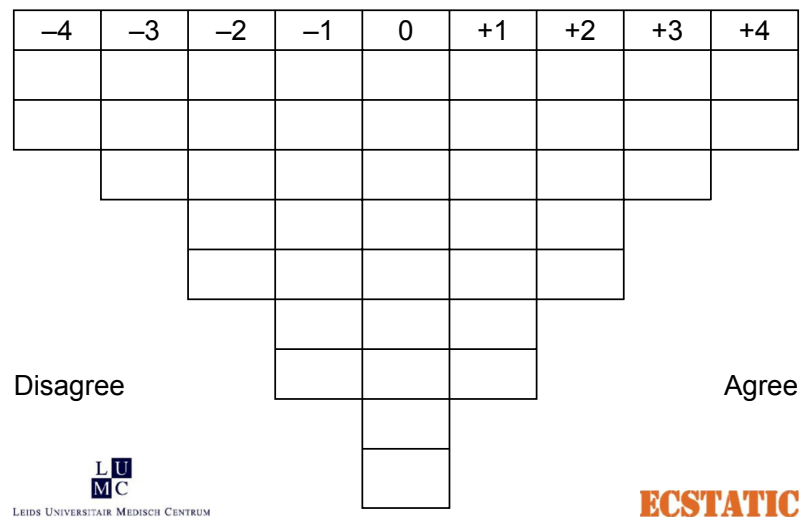

Figure SI Score sheet Q-methodology, the Netherlands, 2015.

\section{Publish your work in this journal}

Patient Preference and Adherence is an international, peer-reviewed, open access journal that focuses on the growing importance of patient preference and adherence throughout the therapeutic continuum. Patient satisfaction, acceptability, quality of life, compliance, persistence and their role in developing new therapeutic modalities and compounds to optimize clinical outcomes for existing disease states are major areas of interest for the journal. This journal has been accepted for indexing on PubMed Central The manuscript management system is completely online and includes a very quick and fair peer-review system, which is all easy to use. Visit http://www. dovepress.com/testimonials.php to read real quotes from published authors.

Submit your manuscript here: http://www.dovepress.com/patient-preference-and-adherence-journal 